Artigos

\author{
Carla Cecília Rodrigues Almeida \\ Universidade Estadual de Maringá
}

\author{
Maria Ligia Ganacim Granado Rodrigues Elias \\ Universidade de São Paulo
}

\title{
O conceito de liberdade como não dominação sob a perspectiva feminista
}

\begin{abstract}
Resumo: O ponto central da teoria de Philip Pettit, referência fundamental no chamado novo republicanismo, é o conceito de liberdade como não dominação: uma pessoa livre é aquela que não vive sob desejo arbitrário ou dominação de outros. Para ele, esse conceito crucial unifica os autores neorrepublicanos, a despeito de suas variações analíticas, e pode articular preocupações de vários movimentos contemporâneos, como o feminista. Esse trabalho analisa os pontos de aproximação e tensão existentes entre o republicanismo de Pettit e algumas das preocupações presentes no campo plural e heterogêneo da teoria feminista. Defendemos o argumento de que, se tratado como um regulador político, o ideal de liberdade como não dominação pode ser bastante útil às feministas.
\end{abstract}

Palavras-chave: feminismo; republicanismo; liberdade.

Copyright (๑) 2014 by Revista Estudos Feministas.

\section{Introdução}

Philip Pettit é considerado um dos mais importantes autores do neorrepublicanismo, movimento que revigorou os temas do pensamento republicano no debate teórico contemporâneo. O ponto vital de sua teoria é o conceito de liberdade como não dominação, segundo o qual uma pessoa livre é aquela que não vive sob desejo arbitrário de outras. Para Pettit, esse conceito expressa o cerne das preocupações republicanas e também pode servir às aspirações por liberdade nutridas por socialistas, multiculturalistas, ambientalistas e feministas.

Nosso objetivo é identificar os pontos de aproximação e tensão entre o conceito de liberdade de Pettit e algumas das preocupações da teoria política feminista. Como 
1 Jane MANSBRIDGE e Susan OKIN 1995.

${ }^{2}$ Marilyn FRIEDMAN, 2008. afirmam Jane Mansbridge e Susan Okin, ${ }^{1}$ à pluralidade constitutiva do feminismo subjaz um objetivo comum e geral: o fim da sistemática dominação da mulher. As explicações feministas para tal dominação têm desafiado a teoria política de uma forma mais ampla e, por isso mesmo, elas têm alcançando um status inegavelmente importante para as discussões contemporâneas que envolvem o poder e a liberdade. Não à toa, portanto, interessa a Pettit suscitar um diálogo com as feministas.

Para analisar seu conceito de liberdade a partir de preocupações oriundas do feminismo, tomaremos como referência o exame crítico de Marilyn Friedman, ${ }^{2}$ feminista norte-americana que tem se dedicado ao tema da autonomia e das relações entre feminismo e cidadania. Em Pettit's Civic Republican and Male Domination (2008), Friedman procura oferecer uma resposta direta às pretensões de Pettit em relação ao feminismo e, nessa medida, evidencia, mais uma vez, o poder desestabilizador das críticas às teorias fundadas na ideia de um sujeito unificado e racional, base da autoridade moral, supostamente portador de uma identidade fixa e coerente. Segundo críticas oriundas do feminismo, essa concepção de sujeito ampara a dominação de gênero ao se fundar nas dicotomias razão/sensibilidade, mente/corpo, vida pública/privada, as quais pressupõem a desqualificação moral e política daqueles segundos polos e dos agentes a eles associados.

Mas o exame de Friedman também nos leva a considerar pontos nevrálgicos das dificuldades enfrentadas para quem se propõe uma teoria política que busca desocultar a dominação das relações costumeiramente identificadas como privadas sem, no entanto, abrir mão de uma defesa intransigente das liberdades individuais, o que exige reconhecimento e valorização dos traços distintivos entre existência privada e pública. Levando em consideração essas dificuldades, argumentamos neste artigo que o conceito de liberdade como não dominação pode ser entendido como um regulador político que preserva distinções entre vida pública e privada e, simultaneamente, mantém abertas as portas da primeira aos reclamos por liberdade que possam partir da segunda. Assim, a despeito da pertinência das críticas de Friedman, julgamos que o conceito de Pettit sobrevive a elas tendo em vista preocupações oriundas do feminismo. Cumpre notar que suas críticas nos interessam na medida em que projetam preocupações mais amplamente associadas ao campo plural e heterogêneo da teoria política feminista. É importante destacar que a teoria republicana de Pettit assim como a teoria feminista são campos complexos de análise, e seus diálogos, aproximações e afastamentos podem se dar sob diferentes frontes. Este artigo não tem a 


\footnotetext{
${ }^{4}$ Philip PETTIT, 1997, p. 140. A tradução a seguir e as demais apresentadas nesse artigo são de nossa autoria: "O republicanismo não apenas pode oferecer uma articulação persuasiva das reivindicações centrais feministas como também fornece uma articulação que possui uma história contínua entre as próprias feministas."
}

pretensão de esgotá-las, mas sim desenvolver o argumento acima mencionado.

Para isso, o artigo está estruturado em três partes. Na primeira, apresentamos o conceito de liberdade como não dominação de Pettit, salientando suas afinidades com preocupações da teoria política feminista. Na segunda, nos dedicamos ao exame das críticas que Friedman dirige a Pettit. Na terceira e última parte, oferecemos algumas alternativas às críticas de Friedman, retomando principalmente a ideia de contestabilidade contida na teoria de Pettit. Dessa forma, fundamentamos o nosso argumento de que, se tratado como um regulador político, o ideal de liberdade como não dominação pode ser muito útil a preocupações da teoria feminista.

\section{A liberdade como não dominação e suas afinidades com preocupaçōes da teoria feminista}

A discordância costuma ser um forte motivador para o diálogo entre autores filiados à mesma ou a correntes teóricas distintas. Mas, entre Pettit e as feministas, são as afinidades de partida, e não as discordâncias, que levam ao interesse mútuo e justificam, para ambos, a necessidade do diálogo, visto que a percepção de tais afinidades contrasta, segundo análise de algumas feministas, com o histórico pouco amistoso existente entre republicanismo e feminismo. Levando em consideração essas mudanças, Anne Phillips ${ }^{3}$ afirma, por exemplo, que, de antagonistas, as duas correntes passaram a ser possíveis amigas.

Para Pettit, essas afinidades têm, na verdade, raízes históricas mais remotas. O autor lembra a forte presença do tema da liberdade em autoras que se preocuparam com a condição feminina em vários momentos históricos e faz referência, inclusive, a Jane Mansbridge e Susan Okin, feministas contemporâneas que, como vimos, afirmam que o objetivo do feminismo, a despeito de sua pluralidade constitutiva, seria o de acabar com a dominação masculina sistemática das mulheres. Para Pettit, o tema central dos republicanos também é a liberdade, e se essa tradição de pensamento muitas vezes foi associada a ideias masculinas de participação e ativismo público, isso se deve, segundo o autor, a uma "má historiografia populista". Se o cerne do republicanismo está na defesa da liberdade, nada justifica que ela se restrinja aos cidadãos do sexo masculino. De tal maneira que, para Pettit, "Not only can republicanism offer a persuasive articulation of the central feminist claims, it also provides an articulation that has had a continuos history within the ranks of feminists themselves." 4 
${ }^{5}$ Anne PHILLIPS, 2004.

6 PHILLIPS, 2004, p. 277. "O que emerge como o pior dos males no cânone republicano é estar exposto à vontade arbitrária de outro; e, ainda que a maior parte da literatura clássica sobre o tema tenha centrado sua atenção crítica nos governos tirânicos com poderes ilimitados, não há razão para que as mesmas questões não possam ser aplicadas à dominação dos empregadores sobre os trabalhadores ou à dominação dos maridos sobre suas esposas." 7 Phillip PETTIT, 1997a.

${ }^{8}$ Referimo-nos ao ensaio Dois Conceitos de liberdadede, de Isaiah Berlin (1959). As duas acepções contrastadas por Berlin são: a liberdade em seu sentido positivo caracterizada como "autodomínio", e a liberdade em seu sentido negativo, concebida como "não interferência". Inicialmente, poderíamos resumir as diferenças entre as duas concepções da seguinte forma: a liberdade negativa corresponderia a "estar livre de", e a liberdade positiva corresponderia a "estar livre para". Enquanto a noção negativa está preocupada em evitar interferência nas ações dos indivíduos, a noção positiva preocupa-se com questões relacionadas à natureza e ao exercício do poder.

9 PETTIT, 2004.
Do lado das feministas, Anne Phillips, ${ }^{5}$ fazendo referência direta às contribuições de Pettit, também reconheceu que um importante ponto de convergência entre Feminismo e Republicanismo está na crítica à dependência e à dominação. Para ela, ao deslocar do centro de suas formulações republicanas os ideais de uma ativa participação política e da busca dos interesses comuns, na mesma medida em que focalizou o tema da liberdade, Pettit contribuiu para a aproximação daquelas duas correntes. Esse movimento característico de sua teoria republicana implicaria, segundo Phillips, numa visão bem menos rígida das divisões entre público e privado, tão recorrentemente remetidas ao republicanismo. Assim, a partir da leitura republicana de Pettit:

Lo que emerge como el peor de los males en el canon republicano es estar expuesto a la voluntad arbitraria de otro; y si bien la mayor parte de la literatura clásica sobre el tema ha centrado su atención crítica en los gobernantes tiránicos con ilimitadas competencias, no hay razón para que las mismas cuestiones no puedan ser aplicables a la dominación de los empleadores sobre los trabajadores o a la dominación de los maridos sobre sus esposas. ${ }^{6}$

Em Republicanism, Philip Pettit ${ }^{7}$ elabora sua teoria republicana fundamentado no conceito de liberdade como não dominação. No capítulo dedicado à apresentação e aprofundamento desse conceito, Pettit retoma as concepções de liberdade positiva e liberdade negativa, consideradas pelo autor como as mais correntes no campo da teoria política, especialmente pelo impacto das formulações de Isaiah Berlin. ${ }^{8}$ Ao retomar a dicotomia entre a liberdade positiva e a liberdade negativa, Pettit tem como objetivo definir o seu conceito como uma terceira possibilidade de entender a liberdade: a possibilidade republicana. Nessa mesma medida, ele também procura desconstruir a associação estabelecida entre liberdade positiva e republicanismo ao defender que figuras importantes dessa tradição se mostraram historicamente preocupadas com uma liberdade entendida em termos negativos. ${ }^{9}$

Pettit enfatiza que a concepção de liberdade como não dominação advém de uma antiga tradição que associa ser livre a não ser dominado ou subjugado por ninguém. O autor procura diferenciar, portanto, a sua concepção de liberdade de uma concepção positiva, porém seu foco principal está no debate com a noção negativa de liberdade. Dessa forma, Philip Pettit desenvolve a ideia de liberdade como não dominação em oposição à ideia de liberdade como não interferência. Seu argumento é o de que a primeira pertence à tradição republicana, 
${ }^{10}$ PETIIT, 1997C.

\footnotetext{
11 PETIT, 1997, p. 8-9. "O liberalismo tem sido associado ao longo dos duzentos anos de seu desenvolvimento e, na maioria de suas variações influentes, com a concepção negativa de liberdade como a ausência de interferência, e com a suposição de que não há nada inerentemente opressivo quanto a algumas pessoas possuírem poder dominante sobre outras, desde que essas não exerçam tal poder nem sejam susceptíveis de exercê-lo."

12 PETTIT, 1996, p. 578. Tradução livre.

${ }^{13}$ PETIIT, 1997, p. 55. "O que torna um ato de interferência arbitrária então - arbitrária no sentido de ser perpetrado sob bases arbitrárias? Um ato é perpetrado sob bases arbitrárias, nós podemos dizer, se este ato é sujeito apenas ao arbitrium, à decisão ou julgamento do agente; o agente estava em uma posição de decidir ou não, ao seu prazer."
}

enquanto a segunda corresponde à forma liberal de pensar o tema da liberdade.

Tanto a ideia de liberdade como não interferência como a ideia de liberdade como não dominação evocam a noção de interferência. Interferência constitui-se como um ato intencional pelo qual os agentes são responsáveis. Os atos de interferência podem ser uma coerção tanto do corpo como da vontade, ou uma manipulação. Incluem atos que reduzem as alternativas de escolha ou que aumentam o custo associado a uma escolha. Assim, a interferência pode diminuir as possibilidades de escolha do indivíduo ou aumentar seus custos para optar por uma determinada alternativa. ${ }^{10}$

Embora as duas concepções possuam a meta "negativa" de evitar a interferência, há uma distinção entre elas no que diz respeito a que tipo de interferência deve ser evitada. Segundo Pettit, a forma liberal de entender a liberdade tem como foco as interferências de fato, e qualquer interferência consiste em uma diminuição da liberdade sob essa concepção:

[...] liberalism has been associated over the two hundred years of its development, and in most of its influential varieties, with the negative conception of freedom as absence of interference, and with the assumption that there is nothing inherently oppressive about some people having dominating power over others, provided they do not exercise that power and are not likely to exercise it. ${ }^{11}$

O que diferencia a ideia republicana de liberdade é o fato de seu foco de preocupação não estar em qualquer tipo de interferência, mas sim nas interferências arbitrárias. Para Pettit, toda interferência arbitrária, ou mesmo a possibilidade desta, são formas de dominação. A arbitrariedade acontece quando um indivíduo tem a possibilidade de agir de acordo com sua vontade, seu arbitrium, sem levar em conta aqueles que serão atingidos por suas ações. Dessa forma, alguém domina ou subjuga outro na extensão da capacidade que tem "(1) de interferir (2) com impunidade e de acordo com sua vontade (3) em certas escolhas que os outros estão em posição de fazer". ${ }^{12}$ Pettit explica o que são atos arbitrários da seguinte forma:

What makes an act of interference arbitrary, then arbitrary in the sense of being perpetrated on an arbitrary basis? An act is perpetrated on an arbitrary basis, we can say, if it is subject just to the arbitrium, the decision or judgment, of the agent; the agent was in a position to choose it or not choose it, at their pleasure. ${ }^{13}$

Tendo em vista que a preocupação da liberdade republicana tem seu foco na arbitrariedade, e que, por sua 
14 Pettit e Frank Lovett, 2009.

vez, a arbitrariedade é entendida como fonte de dominação, tal liberdade irá diferenciar-se principalmente em dois aspectos da liberdade como "mera" não interferência. A primeira diferença trata da possibilidade de não ser livre, de estar em uma situação de domínio sem sofrer interferência de fato. Segundo Pettit, para os republicanos pode haver dominação mesmo sem haver uma interferência efetiva quando alguém possui o poder de interferir arbitrariamente, mesmo que de fato não o faça. Pettit recorre à tradição republicana para enfatizar que uma pessoa, enquanto viver à mercê da vontade de outra, estará sendo dominada.

A segunda diferença refere-se à possibilidade de ser livre mesmo sofrendo interferência. Essa condição está diretamente ligada ao papel das leis para o Estado Republicano. Para o republicanismo, as leis que correspondam aos pensamentos e interesses gerais podem até ser consideradas formas de interferência, mas não se constituem numa forma de dominação, consequentemente não comprometem a liberdade. A grande condição para que a lei não se constitua como uma interferência arbitrária é ela levar em conta todos aqueles que por ela serão afetados, ou seja, representar uma regra justa.

Para Philip Pettit, a maximização da não dominação deve ser a principal motivação de um governo republicano. Isso implica não só tornar improvável uma dominação, mas também restringir qualquer possibilidade de interferência arbitrária. Desfrutar a liberdade no sentido republicano requer uma esfera de escolhas na qual não temamos sofrer controle ou poder arbitrário de outros. Tal esfera será resiliente quando os indivíduos forem protegidos por instituições que não possam ser subvertidas. Dessa forma, a genuína liberdade como não dominação requer a extensão igual de direitos de cidadania para todos. Esse pacote de direitos de cidadania constitui uma expressão legal do status de "pessoa livre" em uma dada sociedade. ${ }^{14}$

Desse modo, viver sob o jugo de um senhor bondoso, de um marido generoso, por exemplo, não significa ser livre. Ao falar das convergências entre o republicanismo de Pettit e as preocupações feministas, Philips sublinha que Pettit emprega exemplos da dominação de gênero para ilustrar que o seu conceito iria além do conceito de não interferência. Do mesmo modo, Friedman (2008) reconhece a importância para as feministas de um conceito de dominação que não se restrinja a "mera" interferência. Para ela, essa restrição pode gerar visões enganosas segundo as quais a melhor coisa que uma pessoa pode fazer pela outra é deixar o seu caminho livre. Assim, podemos dizer que ambas concordam que a liberdade como "não interferência", associada aos postu- 


\footnotetext{
${ }^{15}$ Essa é uma discussão bastante ampla. Podemos encontrar alguns argumentos em Roberto Gargarella (1999), em especial no capítulo 6 , e em Pettit (2004) e Pettit e Lovett (2009).

${ }^{16}$ Joan LANDES, 1998.
}

lados liberais, é um ideal inferior ao da liberdade como "não dominação".

As dominações de gênero avançam sobre aquelas que seriam as linhas que dividiriam o "público" do "privado", e a teoria política comprometida em entender e desafiar a dominação exige uma interpretação de tais esferas. As formulações de Pettit e o seu foco na dominação são atraentes para a teoria política feminista na medida em que o seu ideal de liberdade esquiva-se dos habituais posicionamentos liberais e republicanos, ${ }^{15} \mathrm{com}$ importantes implicações para o entendimento de esfera pública e privada, tema-chave para a teoria feminista.

Como podemos depreender do que afirmou Joan Landes, ${ }^{16}$ o desconforto das feministas com o republicanismo e o liberalismo foi elaborado a partir da maneira como suas fronteiras foram, tradicionalmente, reconhecidas e nomeadas. Segundo ela, como os republicanos, as feministas valorizam a participação e a esfera pública, pois visam trazer para o debate público as estruturas e as relações desiguais e hierárquicas historicamente construídas sob os mitos universais do indivíduo soberano e racional. Como os liberais, elas veem a necessidade de expandir os direitos individuais, já que o próprio reconhecimento de que temos direito à liberdade individual e a um interesse próprio é fundamental para desconstruir as ficções de unidade que oprimem e silenciam as diferenças. Por isso, a autora observa a desconfortável posição das feministas com essas duas tradições.

Entretanto, o conceito de liberdade como não dominação, defendido por Pettit como tipicamente republicano, não vem acompanhado pela supervalorização de uma esfera sobre a outra. Ao contrário, mais do que entender que a dominação é um mal independente da esfera em que se instaura, seu conceito leva a considerar as interdependências entre garantia dos direitos individuas e valorização da esfera pública. E é nesse olhar que valoriza igualmente esfera pública e privada e suas interconexões que parece residir a atração das feministas pelo republicanismo de Pettit.

\section{Críticas feministas à liberdade como não dominação}

Ainda que reconheça sua afinidade com as demandas feministas, Friedman ${ }^{17}$ identifica que, sob a própria ótica delas, o conceito de liberdade de Pettit apresenta problemas. Em síntese, seu argumento é o de que a dominação como mera capacidade de agir arbitrariamente sobre outras pessoas é, em determinados aspectos, muito exigente e, em outros, muito fraco. É muito exigente no que diz respeito à 
aceitação da dominação como mera capacidade e muito fraco no que se refere a excluir da dominação a não arbitrariedade.

O conceito é exigente porque uma pessoa não pode ser punida pela mera capacidade de interferir arbitrariamente nas escolhas de outras. Considerando as relações de gênero, Friedman diz que o reconhecimento da dominação masculina como um problema estrutural e institucional não justifica que os homens, individualmente, possam ser punidos por estarem numa condição de mera capacidade de dominar as mulheres, afinal, é preciso aceitar que a ação propriamente dita faz uma diferença fundamental. Até porque, afirma a autora, o controle sobre a mera capacidade das pessoas de dominarem outras exigiria um Estado Totalitário, aniquilador do direito à intimidade.

Para Friedman, é importante também distinguir a mera capacidade de dominar da dominação de fato, porque a capacidade das pessoas de interferirem arbitrariamente na vida de outras pode, em muitas situações, ser intrínseca à capacidade para agir em seu benefício. Aqui ela fala especificamente das atividades que envolvem - "cuidado" e que são ancoradas por relações de dependência para suprir necessidades básicas. Essas relações fazem parte da experiência humana e implicam relações desiguais de poder. Nesse caso, a capacidade que uma pessoa tem para interferir arbitrariamente na vida de outras corresponde também à capacidade para proteger e satisfazer necessidades básicas de pessoas dependentes. Considerar dominação como mera capacidade iguala, portanto, dominador e cuidador, pessoa dominada e pessoa cuidada. Segundo a autora, as distinções entre "cuidar" e "dominar" precisam ser reconhecidas, inclusive para que suas fronteiras possam ser preservadas.

Por outro lado, Friedman afirma que o conceito de dominação como mera capacidade de interferir arbitrariamente é fraco se consideramos a possibilidade de coexistência entre dominação e não arbitrariedade. Isso porque, vistas a partir de uma perspectiva mais ampla e integral, nas relações hierárquicas, a subordinação pode se tornar moeda de troca para pessoas que ocupam posições desvantajosas na estrutura social. Esse é o caso típico das relações entre homens e mulheres, nas quais os primeiros, como provedores, podem agir em benefício genuíno de suas esposas e famílias, com suas anuências, ao passo que também, por conta dessa mesma posição, as dominam. Em casos como esses, em algum grau as/os dominadas/os não são simplesmente passivas/os na relação e, portanto, a arbitrariedade não seria o melhor termo para qualificar sua posição diante do polo dominador. 


\begin{abstract}
${ }^{18}$ Segundo Alisson M. Jaggar (1996), a atenção teórica das autoras que trabalham nessa vertente recai na natureza da moralidade e seu projeto é contestar todas as formas pelas quais a ética ocidental excluiu as mulheres ou justificou sua subordinação. Como é comum no feminismo, as formulações dessa vertente são alvos de fortes críticas entre feministas que as acusam de valorizar demasiadamente as relações privadas em detrimento das públicas e de defender uma suposta superioridade moral das mulheres. Sem desejar entrar no mérito da pertinência desses apontamentos, é importante sublinhar que, mesmo entre as que são críticas, há o reconhecimento de que as autoras dessa vertente prestam uma preciosa contribuição ao tematizar a experiência moral feminina e mostrar, assim, a diversidade do fenômeno moral.

19 TRONTO, 1997, p. 196.
\end{abstract}

No conjunto, as críticas de Friedman expõem importantes preocupações oriundas do campo feminista. As privilegiadas nesse trabalho correspondem àquelas associadas, em especial, a sua vertente denominada "ética do cuidado" ou "ética feminista". ${ }^{18}$ Assim, ao trazer o tema do "cuidado" e discutir suas implicações para as relações de dependência e dominação, os argumentos da autora tornam mais complexa a empreitada de traçar fronteiras entre autodeterminação e dominação. Seus exemplos mostram que, pela ótica das relações não usualmente consideradas pela teoria política, ou seja, as relações que envolvem o cuidado e a dependência, as posições dos indivíduos comportam mais ambiguidades e nuances do que podem captar as formulações baseadas em binarismos claramente identificáveis. Conforme argumenta Joan C. Tronto:

Cuidar desafia a visão de que a moralidade começa quando e onde indivíduos racionais e autônomos confrontam-se mutualmente para executar as regras da vida moral. Em vez disso, nos permite ver a autonomia como um problema com o qual as pessoas têm de lidar o tempo todo nas suas relações com os iguais e com aqueles que as ajudam ou delas dependem. ${ }^{19}$

As relações de cuidado e dependência não são tratadas pelos cânones do pensamento político ocidental porque estas não envolveriam a moral, não implicariam julgamentos, já que estariam no terreno das necessidades. De acordo com Tronto, o problema é que, como elas não estão sob o crivo da justiça, nós não temos como garantir a necessária distinção entre "cuidar" e "dominar", nem como julgar quando uma dependência se traduz em dominação. E é para isso que Friedman deseja chamar atenção quando nota a necessidade de reconhecermos as distinções entre dependência e dominação, cuidador e dominador, ou mesmo reconhecermos quando há o deslizamento de um polo para outro.

Ao silenciamento teórico das relações que envolvem o cuidado/dependência e à negação do seu estatuto moral subjaz o pressuposto de uma rígida separação entre liberdade/necessidade, razão/sensibilidade, mente/corpo. E é o tratamento dicotômico desses pares que permite retirar do problema da liberdade a complexidade que the é intrínseca e que o exemplo das relações de cuidado e dependência deixa evidente. O tratamento dicotômico daqueles pares permite simplificações, como admitir a existência de uma fronteira fixa e claramente identificável entre o terreno da moral e o terreno da necessidade tanto quanto entre a autodeterminação e a dominação. 
${ }^{20}$ Alisson JAGGAR, 1996.

É para essa dificuldade que nos alerta o exemplo de Friedman a respeito das relações entre marido e mulher, nas quais ela indica a possibilidade de coexistência entre dominação e não arbitrariedade mediante estruturas sociais que distribuem hierarquicamente os indivíduos na sociedade. Os apontamentos de Friedman nos chamam a atenção para o fato de que as fronteiras entre autodeterminação e dominação não podem ser tão facilmente traçadas como supõem as concepções dicotômicas e fixas de sujeito, que simplificam e silenciam sobre um conjunto de relações humanas.

Como podemos sugerir a partir das considerações de Jaggar, ${ }^{20}$ o sujeito moral que ampara aquelas dicotomias é questionado pelo feminismo e outras correntes porque supõe um ser descarnado, separado, unificado e racional, similar a todos os outros sujeitos. Como se sabe, o feminismo e outras correntes têm contestado essa concepção ao chamarem a atenção para o caráter fragmentado, dinâmico, contextual e sempre precário e parcial das identidades que constituem os sujeitos.

Do nosso ponto de vista, os argumentos de Friedman, lidos a partir dessas considerações críticas, reclamam um conceito de liberdade ao mesmo tempo mais dinâmico e contextual, que seja capaz de abrigar a complexidade intrínseca das situações - multifacetadas - que envolvem as relações humanas. Mas será que devemos concordar com Friedman que o conceito proposto por Pettit não responde, em alguma medida, satisfatoriamente a essas exigências?

\section{A liberdade como não dominação como regulador político}

O nosso argumento neste artigo é o de que, a despeito das críticas de Friedman, o ideal de liberdade como não dominação de Pettit pode ser bastante pertinente para causas feministas se entendido como um regulador político. Isso implica não abordá-lo como uma definição fixa do que é ser livre ou estar sob dominação, mas compreendê-lo como um filtro de entrada de reclamos na esfera pública, ou como um parâmetro de julgamento da pertinência dos reclamos diversos e variados referentes à dominação. Desde essa perspectiva, percebemos que suas potencialidades políticas superam as críticas de natureza normativa apresentadas por Friedman, já que torna a esfera pública significativamente mais porosa sem que suas fronteiras sejam diluídas.

O próprio Pettit já havia mostrado preocupação em dotar seu conceito de certa maleabilidade ao admitir que dominação e liberdade, mais do que pares dicotômicos que envolvem uma questão de "tudo ou nada", se concretizam 
${ }^{21}$ PETTIT, 1997C. em graus variados. Como ele afirma, a não dominação pode variar em extensão e intensidade porque os agentes têm uma capacidade maior ou menor de interferir. A capacidade de interferência que uma pessoa tem sobre outra pode ser mais ou menos séria e pode estar disponível com mais ou menos custo. Então, a liberdade também varia em sua extensão, uma vez que pode existir um número maior ou menor de escolhas disponíveis aos indivíduos, e os custos associados a elas também podem ser mais ou menos significativos. ${ }^{21}$

Do ponto de vista de preocupações feministas, como mencionamos, a pertinência de conceber a liberdade como não dominação como um regulador político está no fato de que, assim, garantimos ao mesmo tempo o não isolamento da esfera privada sem abrir mão do reconhecimento de traços distintivos entre ela e a esfera pública. Para melhor compreender essas potencialidades abrigadas no ideal de liberdade como não dominação, temos que entender sua conexão com a ideia de democracia contestatória defendida por Pettit, o que exige trazer para essa discussão outros elementos de sua teoria republicana.

Para tanto, comecemos recordando que uma das críticas de Friedman dizia respeito a considerar dominação como "mera possibilidade" de ação arbitrária, já que isso conduziria ao Estado totalitário. Assim como Friedman, Pettit também se preocupa com a possibilidade de um Estado que exerça dominação sobre os seus cidadãos. Pettit chama de imperium a interferência arbitrária exercida pelo poder público. Segundo o autor, para um Estado não ser fonte de dominação é necessário um regime constitucional e uma democracia que possibilite a contestação. Um regime constitucional comprometido com a liberdade e que não seja manipulado por aqueles que detêm o poder do Estado deve cumprir três condições: "The first condition is, in James Harrington's phrase, that the system should constitute an 'empire of laws and not of men'; the second, that it should disperse legal powers among different parties; and the third, that it should make law relatively resistant to majority will." ${ }^{22}$ Mas, embora indispensável ao Estado republicano, o sistema constitucionalista não é suficiente para assegurar a não arbitrariedade do governo. Afinal, todo sistema de leis deixará certo poder decisório em mãos de autoridades públicas, mas é responsabilidade de um Estado republicano não permitir que esse poder discricionário se torne uma fonte de arbitrariedades. Assim, é necessário que o Estado seja também democrático.

Pettit ressalta a importância da democracia como forma de garantir que a tomada de decisão pública leve em conta o interesse e as ideias daqueles que serão afetados por ela. Para tanto, a democracia tem que ir além de sua 
${ }^{23}$ PETTIT, 2007, p. 323. "[...] podem permitir a tirania da maioria sob a qual os membros de uma minoria estável são tratados como menos que iguais. Elas também podem permitir a tirania de uma elite na qual os governantes, ou seus apoiadores e simpatizantes imediatos, sejam tratados como mais do que iguais."

${ }^{24}$ PETTIT, 1999, p. 180. "Onde o modo eleitoral de democratização dá as pessoas coletivamente um poder indireto de autoria sobre as leis, o modo contestatório daria as pessoas, consideradas individualmente, um limitado e, com certeza um poder indireto de edição sobre essas leis." dimensão eleitoral, pois deve favorecer os cidadãos a expressarem o seu descontentamento diante das decisões públicas, isso é, a democracia deve ter um caráter contestatório. Para o autor, as eleições são instrumentos importantes de controle popular. Referendos e eleições permitem aos cidadãos destituírem e rejeitarem aqueles que usam arbitrariamente o poder do Estado. O povo é o autor último das decisões, uma vez que a seleção daqueles que estão no governo é determinada pela população. No entanto, as eleições são limitadas para garantir o controle do imperium, pois, embora a democracia eleitoral possa fazer com que os governos não sejam totalmente indiferentes aos interesses populares, ela é bastante consistente com a ideia de que o governo deve seguir os interesses da maioria, absoluta ou relativa. As eleições, para o autor, "[...] may allow the tyranny of the majority under which the members of a stable minority are treated as less than equal. And they may allow the tyranny of an elite whereby those in government, or their immediate cronies and supporters, are treated as more than equal." 23

Assim, para Pettit, o Estado republicano, guiado pelo ideal da liberdade como não dominação, deve se comprometer a respeitar não apenas os cidadãos considerados coletivamente, mas também levar em conta os indivíduos separadamente, o que também podemos supor os diversos grupos constituídos no interior de uma sociedade. Segundo o autor, para que a decisão pública não seja fonte de dominação, não é necessário o consentimento individual para cada decisão que o governo irá tomar, o importante é haver a possibilidade de contestação da decisão tomada. O que torna as decisões públicas interferências não arbitrárias é a possibilidade de o indivíduo contestar a decisão tomada, caso a considere contrária aos seus interesses e ideias relevantes. A democracia é entendida como um modelo primariamente mais contestatório do que consensual: "where the electoral mode of democratization gives the collective people an indirect power of authorship over the laws, the contestatory would give people, considered individually, a limited and, of course indirect power of editorship over those laws." 24

Assim, uma democracia que tenha como foco a criação de canais de contestação aumenta as possibilidades de os reclamos que partem da esfera privada serem acolhidos pela esfera pública. Uma característica interessante da ideia de contestabilidade é que não necessariamente todos os assuntos devem ser discutidos, problematizados e colocados em votação. Desse modo, não é pressuposto que teremos um debate público sobre todos os aspectos da vida, nem tudo o que é privado deverá então ser "político". No entanto, a constestabilidade permite que 
${ }^{25}$ YOUNG, 1996, p. 84.

qualquer assunto possa a vir a público. Uma vez que um grupo ou um indivíduo sinta-se em situação de dominação, este pode recorrer às vias de contestação, que devem ser garantidas pela democracia.

Essa perspectiva se afina com as implicações decorrentes do refrão feminista "o pessoal é político". Segundo a visão de Iris Marion Young, esse refrão não deseja diluir as distinções entre esfera pública e privada, mas intenciona defender que "nenhuma pessoa, nem ações, nem aspectos da vida de uma pessoa devem ser forçados à privacidade". ${ }^{25}$ Nesse sentido, a autora deseja, como ela mesma enfatiza, acentuar a orientação do agente, isto é, o direito de o indivíduo retirar-se, ao invés de ser retirado.

Podemos entender então que a liberdade como não dominação serve bem como um regulador político que amplia significativamente a porosidade da esfera pública aos reclamos de dominação, abrindo possibilidades para que relações de dominação socialmente construídas possam ser debatidas, ainda que os indivíduos particulares dos grupos aos quais aquelas relações estejam associadas não sofram, concretamente, a dominação. Afinal, para Pettit, a não dominação está ligada ao conhecimento e reconhecimento comum. Isso significa que desfrutar a não dominação em relação a outro agente - ao menos quando o agente é uma pessoa - exige ser capaz de olhar o outro nos olhos, confiante no conhecimento compartilhado de que você persegue as suas escolhas por um direito publicamente reconhecido. Não vive com medo ou em deferência a outrem.

É importante notar que essa maneira de formular o problema da dominação projeta para o centro das atenções o grau de porosidade da esfera pública. Ou melhor, essa formulação faz a atenção recair nas fronteiras entre esfera pública e privada, não para que seus traços sejam necessariamente reforçados ou atenuados, mas para que suas implicações recíprocas sejam sempre consideradas e debatidas. Assim, do ponto de vista teórico, torna-se pouco relevante determinar se uma relação de dominação pode ser assim definida desde um ponto de vista exterior aos seus agentes, ou se apenas interiormente a eles. Do modo mesmo, aqui também importa pouco o empreendimento teórico voltado à classificação a priori das relações entre livres ou não. Sem desconsiderar a importância das discussões normativas que envolvem questões dessa natureza, o que desejamos sublinhar aqui é a potencialidade política do conceito de liberdade como não dominação para enfatizar que, sim, a priori, toda e qualquer relação pode se transformar em objeto de debate público.

Portanto, apesar das considerações de Friedman, observamos mais aproximações do que incompatibilidades 
entre o ideal de não dominação de Pettit e as preocupações feministas. Entendida para além de um conceito filosófico, a liberdade como não dominação, enquanto um regulador político, é uma grande aliada na luta contra a dominação das mulheres.

\section{Referências}

BERLIN, Isaiah. Estudos sobre a Humanidade. São Paulo: Companhia das Letras, 2002.

FRIEDMAN, Marilyn. "El feminismo y la concepción moderna de la amistad: dislocando la comunidad". In: CASTELLS, Carme. (Org.). Perspectivas feministas en teoría política. Primera edición. Barcelona: Paidós, 1996. p. 149-166.

."Pettit's Civic Republicanism and Male Domination." In: LABORDE, Cécile and MAYNOR, John (Eds.) Republicanism and Political Theory. Oxford: Blackwell publishing: 2008. p. 246-268.

GARGARELLA, Roberto. Las teorías de la justicia después de Rawls: um breve manual de filosofia política. Barcelona: Paidós, 1999.

JAGGAR, Alisson M. "Ética feminista: algunos temas para los anõs noventa". In: CASTELLS, Carme (Org.) Perspectivas feministas en teoría política. Primera edición. Barcelona: Paidós, 1996. p. 167-184.

LANDES, Joan B. "Introduction." In:___ (Ed.). Feminism, the Public, and the Private. Oxford: Oxford University, 1998.

OKIN, Susan; MANSBRIDGE, Jane. "Feminism." In: GOODIN, RobertE.; PHILLIP, Pettit (Orgs). A companion to contemporary political philosophy. Blackwell companions to Philosophy. 1995. p. 269-290.

PETIIT, Philip; LOVETT, Frank. "Neorepublicanism: a normative and Institutional research program." Annual Review political science, v. 12, p. 11-29, 2009. Disponível em: $<\mathrm{http}$ ://www.annualreviews.org/toc/polisci/12/1 > . Acesso em: 6 fev. 2012.

PETTIT, Philip. "Joining the dots." In: BRENNAN, Geoffrey et al. (Eds.). Common minds: themes from the philosophy of Philip Pettit. Oxford: OUP, 2007.

"Liberalismo y republicanismo". In: OVEJERO, Félix;

MARTí, José Luis; GARGARELLA, Roberto (Orgs.). Nuevas ideas republicanas: autogobierno y libertad. Barcelona: Paidós, 2004. p. 115-135.

. Republicanism. A theory of freedom and government. Oxford, Oxford University Press, 1997a. "Freedom with Honor: A Republican Ideal." Social Research, New York, v. 64, n. 1, p. 52-76, 1997b.

. "Republican Political Theory." In: VINCENT, Andrew

(Ed.). Political Theory: Tradition, Diversity and Ideology, 
Cambridge: Cambridge University Press, 1997c. p. 112132.

"Freedom as Antipower." Ethics, Chicago, v. 106, n. 3, 1996, p. 576-604.

PHILLIPS, Anne. "Feminismo y republicanismo: es ésta una alianza plausible?" In: OVEJERO, Félix; MARTÍ, José Luis; GARGARELLA, Roberto (Orgs.). Nuevas ideas republicanas: autogobierno y libertad. Barcelona: Paidós, 2004. p. 263285.

TRONTO, Joan C. "Mulheres e Cuidados: o que as feministas podem aprender sobre a moralidade a partir disso?" In: JAGGAR, Alisson M.; BORDO, Susan R. (Orgs). Gênero, Corpo e Conhecimento. RJ: Rosa dos Ventos, 1997. p. 186-203.

YOUNG, Iris Marion. "A imparcialidade e o público cívico: algumas implicações feministas da teoria moral e política". In: BENHABIB, Seyla; CORNELL, Drucilla. (Orgs.). Feminismo como crítica da modernidade. Releitura dos pensadores contemporâneos do ponto de vista da mulher. Rio de Janeiro: Rosa dos Tempos, 1987. p. 66-86.

[Recebido em $1^{\circ}$ de março de 2012 , reapresentado em 9 de maio de 2013 e aprovado em 20 de junho 2013]

Concept of Freedom as Non-Domination under the Feminist Perspective

Abstract: The central point of Philip Pettit's theory, fundamental reference in the so-called neorepublicanism, is the concept of freedom as non-domination: a free person is one who does not live under arbitrary will or domination of others. For him, this crucial concept unifies new republican's authors, despite their analytical variations, and can articulate concerns of several contemporary movements such as the feminist. This paper analyzes the closeness and tension between Pettit's republicanism and some of the concerns present in the plural and heterogeneous field of feminist theory. We advocate the argument that, if treated as a political regulator, the ideal of freedom as non-domination can be very useful to feminists.

Key Words: Feminism; Republicanism; Freedom. 